\title{
ANALYSIS OF THE ASSOCIATED FACTORS OF BOARDING TIME IN YELLOW ZONE PATIENTS IN EMERGENCY DEPARTMENT
}

\author{
Ahsan Ahsan, Fitrio Deviantony, Setyoadi Setyoadi \\ School of Nursing, Faculty of Medicine, Universitas Brawijaya \\ Email: ahsanfkub@yahoo.com
}

\section{ABSTRACT}

Introduction: Patient's visits to the emergency room increase in number every year. The increasing number of hospital visits is directly associated with the increasing number of patients who wait in the emergency department. The yellow zone is a part of the emergency room that has become a place for the most increased patients to enter. This situation causes boarding time patient longer than usual. The aim of this research was to analyse the various factors that have been associated with boarding time in the yellow zone emergency department. Methods: This research was an analytic observational study with a cross-sectional approach. The number of samples was 78 respondents who were recruited with a non-probability sampling technique. The univariate and bivariate analysis was utilized to test the relationship between the variables. A further statistical test was conducted with linear regression to understand the most dominant factor. Results: The results showed a significant relationship between transfer time, laboratory turnaround time, diagnostic time, time arrival, insurance coverage, ratio nurse and patient and boarding time. Furthermore, multivariate analysis with linear regression showed a significant association between transfer time, laboratory turns around, and the ratio of nurses to patients with the boarding time. Conclusions: The findings from this study show that patient boarding time in the yellow zone should consider several factors. This research provides the output of the initial data as one of the basic considerations for service management and team minimum service standards in hospitals.

Keywords: boarding time, emergency department, yellow zone

\section{INTRODUCTION}

The visitation of patients in the Emergency Department (ED) is growing every year. The increase of this situation is by about $30 \%$ in hospitals around the world (Bashkin et $a l ., 2015)$. Increasing the number of hospital visits clearly affects the increasing number of patients who enter the emergency room. The emergency room unit is an area located in the hospital that is used to perform standard emergency, acute and urgent care (Geelhoed and de Klerk, 2012). Caring in the emergency phase is used to stabilize patients who have disorders from injuries and other sources that require resuscitation and patients who have a certain degree of injury and illness (Australian College for Emergency Medicine, 2015). The data entry of patients who come into the ED in Indonesia is approximately $4,402,205$ patients or $13.3 \%$ of all visits to hospitals (MoH, 2015). Data for the ED patients who visited the emergency room in East Java in 2014 amounted to 8,201,606 cases. Looking at the district level, the data of the visits in Tulungagung in 2014 was 29,877 cases (Dinkes Provinsi Jatim, 2015).

The patient condition who wait too long in the ER will hamper the service process in the emergency department. Fast and precise services are most needed in the emergency installation (Ducharme et al., 2008). The length of time patients in the yellow zone could be due to a mismatch between the number of patients, patient beds and the number of health personnel. An excessive number of patients causes in increased check-up time for other patients, increased waiting time, and prolonged waiting time for returning patients, and patients who will be hospitalized. This condition is called boarding time (Singer et al., 2011). Quality Control Standard of RSUD Dr. Iskak Tulungagung explained that the patient waiting period after the inpatient decision becomes one of the indicators of hospital quality control. So this research focuses on it, as a further hospital evaluation material.

The number of patients per day in the yellow zone can reach 36 patients per day, coming in during the morning, day and night shift. The number of beds in the yellow zone in the ED room is 9 beds with the total number of nurses in the yellow zone being 21 people divided into 5 people per shift. The number of patients boarding for more than 6 hours per day can reach 10 patients. The results of the interview with the team leader in the yellow zone can help to identify the causes of boarding due to the number of limited resources, not being well organised, the results of the laboratory requiring a lot of time, the time to diagnose the disease being longer than usual, the 
Table 1. Demographic characteristic of the respondents

\begin{tabular}{llll}
\hline \multirow{2}{*}{ Gender } & & $\mathbf{n}$ & \% \\
\cline { 2 - 4 } \multirow{3}{*}{ Insurance coverage } & Men & 43 & 55.1 \\
\cline { 2 - 4 } & Women & 35 & 44.9 \\
\hline \multirow{2}{*}{ Number patient } & General & 43 & 55.1 \\
\cline { 2 - 4 } & BPJS & 30 & 38.8 \\
\cline { 2 - 4 } & Jasa Raharja & 5 & 6.4 \\
\hline \multirow{2}{*}{ Age } & Mean & 16 \\
\hline
\end{tabular}

Table 2. Result of the bivariate analysis

\begin{tabular}{lccc}
\hline \multicolumn{1}{c}{ Variable } & Test & p-value & r \\
\hline Boarding Time-Transfer Time & Pearson & 0.000 & 0,747 \\
Boarding Time-Laboratory Turn-around Time & Pearson & 0.000 & 0,693 \\
Boarding Time-Diagnostic Time & Pearson & 0.000 & 0,462 \\
Boarding Time-Time of arrival & Spearman & 0.263 & $-0,128$ \\
Boarding Time-Insurance Coverage & Spearman & 0.980 & $-0,003$ \\
Boarding Time-Ratio between nurse-patient & Spearman & 0.000 & $-0,638$ \\
\hline
\end{tabular}

Table 3. Multivariate analysis among the variables

\begin{tabular}{lllrrrc}
\hline \multicolumn{1}{c}{} & \multicolumn{1}{c}{$\mathrm{S}$} & $\mathrm{SE}$ & $\mathrm{t}$ & $\mathrm{p}$ & $\mathrm{F}$ & Adj R2 \\
\hline Boarding time & & & & & 16.342 & .134 \\
Transfer time & -.300 & 212.157 & -3.784 & .000 & & \\
Laboratory turnaround time & .452 & .199 & 4.367 & .000 & & \\
Diagnostic time & .129 & .153 & 1.207 & .231 & & \\
Ratio nurse and patient & .155 & 1.136 & 2.163 & .034 & & \\
\hline
\end{tabular}

number of patients who came in on the day shift being more than in other shifts, and the bed occupancy time for patients from the ED becoming a factor that causes the boarding time to be longer than usual. The speed of patient care in the Emergency Department can determine the prognosis of the next patient, and obtain optimal results in the care of the patient. The aim of this research was to analyse the various factors that have been associated with boarding time in the yellow zone emergency department.

\section{MATERIALS AND METHODS}

This research used a cross-sectional study approach. The aim of this study was to identify the determinants factors related to health-related events and problems. Data collection was taken from June to July 2017, and this research was conducted at the Emergency
Unit of the RSUD Dr. Iskak Tulungagung. The population of this study was the patients who came to the yellow zone emergency room; 1,080 patients per month. The sampling technique used non-probability sampling which used the rule of thumb with the number of samples, which was 5 to 50 times the number of independent variables (Sastroasmoro and Ismael, 2011). The sample size for this research was 78 respondents. The subjects in this study have inclusion criteria; patients who were in the yellow zone of the ED $>6$ hours. The exclusion criteria for this research were patients who were forced to leave the hospital, patients who had not been examined by the doctor and patients who were discharged or referred to another hospital.

This research was conducted by direct observation method using the instrument of data collection sheet and observation guidance sheet 
and validated by medical record. We analyzed the dependent and independent variable correlation using bivariate analysis with Spearman test and multivariate analysis with linear regression test. P-value $\leq 0.05$ was considered statistically significant. Statistical analysis was performed under SPSS (Statistical Package for the Social Sciences) 14.0 (SPSS Inc. Chicago, IL, USA).

The study was carried out in accordance with the Code of Ethics of the World Medical Association (Declaration of Helsinki) for experiments in humans and approved by the Ethics Committee on Faculty of Medicine, Universitas Brawijaya. Written informed consent was obtained from all study participants.

\section{RESULTS}

\section{Distribution of respondent characteristic}

The demographic characteristics showed that the respondents were mostly male $(55.1 \%)$ and the rest female $(44.9 \%)$. The types of insurance coverage held by the respondents were also identified. Half of the respondents had no insurance $(55.1 \%)$. The remaining respondents used BPJS (37.5\%), and Jasa Raharja (6.4\%). The average number of patients coming to the ER was 16 patients per shift, with the minimum number recorded at the time of the shift guard change being 9 patients and the highest number of patients on one shift being 28 patients. The age of the respondents ranged from 13 years old to 76 years old, with the average age of the respondents being 52.4 years (Table 1 ).

Variable of patient transfer time in RSUD dr Iskak Tulungagung mostly had about 634.55 minutes or 10 hours 57 minutes. Thus, the fastest time was 3 hours 41 minutes and the longest time was 22 hours. The return time of laboratory results was mostly done for 7 hours 9 minutes with the fastest time was 1.8 hours and the longest time is 13.6 hours. Most diagnostic timings were performed for 57.77 minutes with the fastest diagnostic timing being 20 minutes and the longest diagnosis time of 98 minutes. The average value of the waiting time variable of patients after inpatient decision was decided about 909 minutes or 15.15 hours and the lowest patient waiting time after the inpatient decision was 365 minutes or 6 hours and the highest waiting time was 14.22 minutes or 23.7 hours.

In table 2 the variables most closely related to the patient waiting time after the inpatient decision was the patient transfer time (0.747), laboratory return time (0.693) and diagnosis time (0.462). Table 2 explained that there is a significant correlation between the dependent variable (boarding time) with the three independent variables (patient transfer time, laboratory turn-around time and diagnosis time), where the $\mathrm{p}$-value $=0.00$. A simple linear regression was calculated to estimate the association between boarding time and the other variables. Table 3 explained that A significant regression equation found that transfer time (beta $=-0.30 \quad(212.15), \quad \mathrm{p}<0.000), \quad$ laboratory turnaround time (beta $=0.452(0.199), \mathrm{p}<0.000)$, and the ratio nurse and patient (beta $=0.155$ (1.136), $\mathrm{p}<0.034)$.

In the multivariate test the following equations are obtained:

$Y=$ constanta $+a 1 X 1+a 2 X 2$.

$Y=681.212+0.620$ (patient transfer time) +2.636 (diagnostic time)-861.011 (comparison of nurses and patients) (see in the discussion below).

\section{DISCUSSION}

This study found out that the longer time it takes to order boarding time in the yellow zone, the faster it takes the patient's to move to the room. The boarding time recommended by the hospital is no more than six hours. This is in accordance with research which states that the decision-making process related to medical decisions in Indonesia is determined by culture, where decision-makers related to medical treatment is the oldest member of the family. A similar study conducted by Hodgins et al. (2011) mentioned that 41,256 patients treated in the ER during full conditions that resulted in patient boarding time leading to death, decreased by more than 2 hours (Hodgins, Moore and Legere, 2011).

The univariate analysis of the laboratory turnaround time showed that the minimum time for the laboratory results to the ED was 110 minutes and the maximum value was 920 minutes. All patients treated should have laboratory tests carried out related to the 
condition experienced by the patient. Prior research in accordance with these results is shown in a study conducted by Steindel \& Howanitz (2001) which states that laboratory tests were performed in $>50 \%$ of patients visiting the ER and who were hospitalized, including those who were discharged (Steindel and Howanitz, 2001). The return time of the laboratory results is the period of time from the physician's order for a blood test until the results arrive at the ER, with a target time of $<60$ minutes (Hawkins, 2007).

The study found that both variables also have a strong relationship with positive value. It means that the longer the diagnosis time is raised to, then the boarding time of the patient in the yellow zone will be longer, and vice versa when the diagnostic time is faster, then the patient waiting time in the yellow zone of the ED will be shorter as well. This is in accordance with the research put forward by Boyle A et al., (2012), stating that the delay of diagnosis is defined as the time from the patient arriving up until the medical diagnosis arises(Boyle et al., 2012). This variable also enters the framework described by (Rabin et al., 2012), which is where this variable enters the throughput factor component in the described framework overcrowding model.

The result of the bivariate test using a Spearman test on arrival time with boarding time showed no statistical significance. Differences in the results of the study as revealed by Powell et $a l .$, (2012) are where the study explains that the arrival time during the day has the possibility of patient waiting time after the decision of hospitalisation being higher(Powell et al., 2012). Bashkin et al. (2015) in his study also explained the related matters where he found the result that $52 \%$ of patients enter the ED in the morning shift and $48 \%$ are divided into the day shift and night shift. The difference in this result is probably due to the homogenized sample size of the subject so that the variable has no significant relationship in relation to each shift. Another thing that can cause the absence of a relationship between the variable of arrival time and boarding time is the number of patients experiencing boarding time on each shift.

The result of the bivariate test analysis shows that there is no close relationship between the insurance ownership variable with patient boarding time. Differences occurred when this result was compared with the research conducted by Kennedy et al. (2004), where in his research described that in about $7.7 \%$ of the number of visits during the 12 months, there was a delay or a delay in the services in ER (Kennedy et al., 2004). This occurs due to problems such as service charges which are swollen, and insurance coverage will also cause delayed service, causing the patient's boarding time to increase. In this study, another thing that also became an obstacle was if the patient did not have health insurance. Patients who already have health insurance do not have to bother giving their data forward, saving time.

This study found out that there was a s strong correlation between the ratio of the nurses to the patients with the patient boarding time in which the direction of the relationship is negative. This means that when the ratio of nurses with patients per shift is greater, then the patient boarding time is smaller, and vice versa if the ratio of nurses with patients per shift is smaller then the patient waiting time value after the decision of becoming an inpatient is longer. A study described by Wiler et al., (2012) explains how the ratio of nurses with patients on each shift becomes a thing that can affect the duration of service time and the workload of the nurses also increases(Wiler et al., 2012). These results are in accordance with the journal articles published by Zarea (2014) in Iran, mentioning that $78.2 \%$ of nurses are not satisfied with their performance due to the increased workload, safety and salary (Zarea et al., 2014).

Based on the results of the multivariable analysis, where this research used linear regression to predict patient boarding time in the yellow zone, there were the variables of patient transfer time, laboratory turnaround time, diagnostic time and the comparison of nurses with patients per shift. Transfer time, diagnostic time and the proportion of the number of nurses with the patients became the significant factors of the patient's boarding time. This is because long diagnostic timing can lead to long transfer times since transfer decisions are decided when diagnoses are raised. This can be seen from the length of time of diagnosis and the length of 
transfer time. This finding is in accordance with the research described by Lo et al. (2014).

Based on the result above (the equations of the multivariate test) indicates that any delay in transferring the patient to an inpatient room within 60 minutes will increase the patient's boarding time by as much as 0.620 minutes in a patient with a strong correlation strength. This is due to the limitations of the treatment room, where it is characterised by a significant number of patients and a BOR of $75 \%$. These results indicate that bed utilisation in the inpatient wards is higher than the national standard of $60 \%$. This will certainly affect the duration of the patient's boarding time in the ER. With this equation model, it can estimate patient boarding time using the variable time of patient transfer, time of diagnosis determination and ratio of a nurse. The meaning of constant value is that if there is no trust value or variable value, then the participation value is equal to 681.212 minutes. For the variable time of patient transfer, for every addition of 1 minute then there will be an addition of 0,620 minutes. For the variable of the determination time of each diagnosis, there is the addition of 1 minute with an addition of 2,636 minutes. For the nurse comparison variables with patients, the number per guard must be calculated in advance of the number of nurses in one shift then divided by the number of patients in one shift. The bigger the ratio of nurses with patients per shift, is the p-value or waiting time of the patient and whether or not the hospitalisation decision will be smaller.

The results of this study obtained information about the factors relating to patient boarding time in the yellow zone. The limitations in this study are that the researchers only look at the time when the patient was in the ER without considering the amount of space taken and the type of illness that the patient suffers from, so the researchers cannot see which room is used the most to move patients. Another limitation of this research is that the researcher only conducted research in one hospital only, so this research should go on to take time elsewhere with the same characteristics to be able to see the boarding time of patients in the yellow zone in other hospitals.

\section{CONCLUSIONS}

The comparison factors of nurses with patients per shift, diagnostic time, and transfer time have a significant correlation to patient boarding time in the yellow zone. The benefits of this research are that it has identified multifactor causes that have a proximity relationship with patient boarding time in the yellow zone, in particular the time factor of patient transfer, the timing of the diagnosis and the comparison of the nurses and number of patients. It provides the output of the initial data as one of the basic considerations for service management and team minimum service standards for hospitals to enable them to improve the quality of their services and strategies that can be used as a basis for quality development.

\section{REFERENCES}

Australian College for Emergency Medicine (2015) Specialist emergency medicine workforce and training activities 2014. Melbourne: Australian College for Emergency Medicine.

Bashkin, O., Caspi, S., Haligoa, R., Mizrahi, S. and Stalnikowicz, R. (2015) 'Organizational Factors affecting length of stay in the emergency department: initial observational study', Israel journal of health policy research. BioMed Central, 4(1), p. 38.

Boyle, J., Jessup, M., Crilly, J., Green, D., Lind, J., Wallis, M., Miller, P. and Fitzgerald, G. (2012) 'Predicting emergency department admissions', Emerg Med J. BMJ Publishing Group Ltd and the British Association for Accident \& Emergency Medicine, 29(5), pp. 358365.

Dinkes Provinsi Jatim (2015) Profil kesehatan Provinsi Jawa Timur Tahun 2014. Surabaya: Dinkes Provinsi Jatim.

Ducharme J, Tanabe P, Homel P, Miner JR, Chang AK, Lee J \& Todd KH. (2008). The influence of triage systems and triage scores on timeliness of ED analgesic administration. American Journal of Emergency Medicine, 26 (8), 867-873.

Geelhoed, G. C. and de Klerk, N. H. (2012) 
'Emergency department overcrowding, mortality and the 4-hour rule in Western Australia', The Medical Journal of Australia, 196(2), pp. 122-126.

Hawkins, R. C. (2007) 'Laboratory turnaround time', The Clinical Biochemist Reviews. The Australian Association of Clinical Biochemists, 28(4), p. 179.

Hodgins, M. J., Moore, N. and Legere, L. (2011) 'Who is sleeping in our beds? Factors predicting the ED boarding of admitted patients for more than 2 hours', Journal of Emergency Nursing. Elsevier, 37(3), pp. 225-230.

Kennedy, J., Rhodes, K., Walls, C. A. and Asplin, B. R. (2004) 'Access to emergency care: restricted by long waiting times and cost and coverage concerns', Annals of emergency medicine. Elsevier, 43(5), pp. 567-573.

Lo, S. M., Choi, K. T. Y., Wong, E. M. L., Lee, L. L. Y., Yeung, R. S. D., Chan, J. T. S. and Chair, S. Y. (2014) 'Effectiveness of Emergency Medicine Wards in reducing length of stay and overcrowding in emergency departments', International emergency nursing. Elsevier, 22(2), pp. 116-120.

MoH (2015) 'Data dan Informasi Tahun 2014 (Profil Kesehatan Indonesia) [Data and Information in 2014 (Health Profile of Indonesia)]. Edited by P. D. dan I. Kemenkes. Jakarta: Kemenkes.

Powell, E. S., Khare, R. K., Venkatesh, A. K., Van Roo, B. D., Adams, J. G. and Reinhardt, G. (2012) 'The relationship between inpatient discharge timing and emergency department boarding', The Journal of emergency medicine. Elsevier, 42(2), pp. 186-196.
Rabin, E., Kocher, K., McClelland, M., Pines, J., Hwang, U., Rathlev, N., Asplin, B., Trueger, N. S. and Weber, E. (2012) 'Solutions to emergency department "boarding"and crowding are underused and may need to be legislated', Health Affairs. Health Affairs, 31(8), pp. 17571766.

Sastroasmoro, S. and Ismael, S. (2011) Dasardasar metodologi penelitian klinis. Sagung Seto, Edisi 4. ISBN 978-6028674-54-6.

Singer AJ, Thode HC, Viccellio P \& Pines JM. (2011). The association between length of emergency department boarding and mortality. Academic Emergency Medicine, 18 (12), 1324-1329.

Steindel, S. J. and Howanitz, P. J. (2001) 'Physician satisfaction and emergency department laboratory test turnaround time: observations based on College of American Pathologists Q-Probes studies', Archives of pathology \& laboratory medicine, 125(7), pp. 863871.

Wiler, J. L., Handel, D. A., Ginde, A. A., Aronsky, D., Genes, N. G., Hackman, J. L., Hilton, J. A., Hwang, U., Kamali, M. and Pines, J. M. (2012) 'Predictors of patient length of stay in 9 emergency departments', The American journal of emergency medicine. Elsevier, 30(9), pp. 1860-1864.

Zarea, K., Beiranvand, S., Sheini-Jaberi, P. and Nikbakht-Nasrabadi, A. (2014) 'Disaster nursing in Iran: Challenges and opportunities', Australasian emergency nursing journal. Elsevier, 17(4), pp. 190-196. 